\title{
Bubbling to Jetting Transition during Argon Injection in Molten Steel
}

\author{
Miguel A. Barron, Joan Reyes, Dulce Y. Medina \\ Departamento de Materiales, Universidad Autonoma Metropolitana Azcapotzalco, Mexico City, Mexico \\ Email: bmma@correo.azc.uam.mx
}

How to cite this paper: Barron, M.A., Reyes, J. and Medina, D.Y. (2020) Bubbling to Jetting Transition during Argon Injection in Molten Steel. World Journal of Engineering and Technology, 8, 605-616. https://doi.org/10.4236/wjet.2020.84042

Received: August 27, 2020

Accepted: October 11, 2020

Published: October 14, 2020

Copyright (c) 2020 by author(s) and Scientific Research Publishing Inc. This work is licensed under the Creative Commons Attribution International License (CC BY 4.0).

http://creativecommons.org/licenses/by/4.0/

(c) (i) Open Access

\begin{abstract}
Bubbling to Jetting Transition is of the outmost importance in metallurgical processes given that the flow regime influences the refining rates, the refractory erosion, and the blockage of injection nozzles. Bubbling to jetting transition during subsonic bottom injection of argon in molten steel is studied here. The effect of the molten steel height, the injection velocity, the nozzle diameter, and the molten steel viscosity on the jet height and the bubbling to jetting transition is numerically analyzed using Computational Fluid Dynamics. Five subsonic argon injection velocities are considered: 5, 25, 50, 100 and $150 \mathrm{~m} / \mathrm{s}$. Three values of the metal height are taken into account, namely 1.5 $\mathrm{m}, 2 \mathrm{~m}$ and $2.5 \mathrm{~m}$. Besides, three values of the nozzle diameters are considered: $0.001 \mathrm{~m}, 0.005 \mathrm{~m}$ and $0.01 \mathrm{~m}$. Finally, three values of the molten steel viscosity are supposed: $0.0067,0.1$ and $1 \mathrm{~kg} /(\mathrm{m} \cdot \mathrm{s})$. It is observed that for the argon-molten steel system, the bubbling to jetting transition occurs for an injection velocity less than $25 \mathrm{~m} / \mathrm{s}$ and that for the range of viscosities considered, the molten steel viscosity does not exert significant influence on the jet height and the bubbling to jetting transition. Due to the jet instability at subsonic velocities, a second transition, namely jetting to bubbling, is appreciated.
\end{abstract}

\section{Keywords}

Argon Injection, Bubbling to Jetting Transition, CFD, Injection Velocity, Jet Height, Molten Steel, Nozzle Diameter

\section{Introduction}

In the last decades, injection of gases into molten metals has been extensively used at industry for different goals. Inert gases such as argon and nitrogen are employed for bath stirring in order to achieve thermal and chemical homogenization, for removing undesirable non-metallic inclusions, and degasification. 
Oxygen is injected into hot metal or molten steel to remove by oxidation elements such as carbon, silicon manganese and phosphorus. Mixtures of inert gases with oxygen are employed for decarburization of stainless steel melts without excessive losses of chrome. Besides frequently inert gases are utilized as carrier gas to transport powdered reagents into the molten metal for sulfur removal. At low gas flow rate or low injection velocity, a gas injected into a molten metal forms bubbles which grow and detach from the injection nozzle. This is called bubbling regime. The size of the bubbles depends on the balance among the gravity, the inertial, the buoyancy, the surface tension forces and the nozzle size. After detachment, the bubbles ascend to the molten metal surface due to the buoyancy forces, and during their upward travel, commonly breakup and coalescence phenomena are present. Momentum transfer between the gas bubbles and the molten metal is carried out, and as a result, the molten metal becomes stirred. As the gas flow rate and the inlet velocity are increased, a continuous swarm of small bubbles arises. This flow pattern is called jetting regime. Commonly, particularly under the current injection conditions at industry, the formed jet is unstable and after certain distance from the nozzle, the jet is disintegrated into discrete large bubbles [1]. The length of the jet depends, among other factors, on the nozzle diameter, the liquid depth, the gas flow rate or the injection velocity, and the physical properties of the gas and the molten metal.

Bubbling to Jetting Transition (BJT) is fundamental in metallurgical processes given that the flow regime influences the refining rates, refractory erosion, and the penetration of the molten metal into the nozzles [2]. For these reasons, a good knowledge of the flow regime is important: the contacting pattern rules the refining rate; the flow regime governs the extent of refractory erosion in the vicinity of the nozzles; nozzle clogging by molten metal and slag depends on the flow pattern; and from economic reasons, it is required at industry to carry out the reactions faster in smaller reactors [2]. Identification of the BJT is of the outmost importance given the great influence that this phenomenon has on the operational and maintenance costs and the equipment availability of the involved processes. Residence time of bubbles in the molten metal determines the process time and the efficiency and extent of the chemical reactions. Large bubbles collapse at the bath surface and cause slopping and splashing which in its turn cause skull formation on the upper part of the containing vessel. Besides, under the bubbling regime, the nozzle is prone to blockage given that during bubbling detachment molten metal penetrates and solidifies inside the nozzle [3] [4] [5]. Due to the strong market pressures and competition among companies to reduce costs, in recent years, there has been a steadily growing tendency, particularly in the non-ferrous industry, to operate the industrial injection equipment in the jetting regime. For this gas injection regime, the following advantages can be mentioned: the nozzle blockage is significantly reduced, the slopping and splashing phenomena are minimized with proper nozzle design, and the productivity and availability of the equipment are enhanced [4]. The main drawbacks of the gas injection in the jetting regime are the accelerated wear of the vessel refrac- 
tory and the small residence time of the gas and particles in the molten metal.

No uniform criterion exists in the literature to clearly identify the conditions under which the BJT occurs since a multitude of variables participate in that phenomenon. Variables such as forces (buoyancy, viscous, inertial, gravity, surface tension), physical properties of the phases involved (density, viscosity, surface tension), vessel geometry (nozzle diameter, aspect ratio), operating conditions (molten metal height, injection velocity, injection pressure, gas flow rate, nozzle geometry, injection angle, nozzle location, nozzle roughness), flow instabilities (Rayleigh-Taylor, Kelvin-Helmholtz), all of them participate in the setting of the BJT [6]. Physical models, theoretical models and Computational Fluid Dynamics simulations have been employed to analyze the BJT. A fast review of the literature allows identification of some criteria that the researchers have employed to determine the BJT, and many of them are based on the values that take diverse dimensionless number at the moment of the BJT. These numbers are, in alphabetical order, as follows: modified Froude number (Fr), Kutateladze number $(\mathrm{Ku})$, Mach number $(\mathrm{M})$, Reynolds orifice number $(\mathrm{Re})$, and Weber number (We). All of these dimensionless numbers contains at least two of the variables considered above, in accordance to the importance that each author assigns to a particular variable.

Based on physical experiments with several gases and liquids and using high speed cinematography in [7] two regimes of flow, bubbling and steady jetting, are reported as a function of the modified Froude number and the ratio of gas to liquid densities. A transition regime, consisting of periods of steady jetting alternating with periods of pulsing, is observed for modified Froude numbers roughly in the range of 300 to 900 . For these authors the BJT primarily depends on a balance between the inertial forces of the gas flow through the nozzle and the gravity forces of the liquid surroundings the orifice. Flow in gas-stirred ladles is ruled by the Froude number given that the effect of the buoyancy of the injected gas on the inertia of the liquid in the ladle determines flow [3]. Dynamic scaling should hence be based on the Froude number and not on the Reynolds number, which gives the ratio of inertial to viscous forces. Measurements of the interfacial behavior of water-submerged gas jets, with Mach numbers ranging from subsonic to supersonic were performed in [6]. The jetting length scales with the square of the Froude number and a good comparison is reported with experimental observations. In accordance to these authors measurements suggest that both Rayleigh-Taylor and Kelvin-Helmholtz instabilities are nearly equally responsible for ruling the dynamics of the jet boundaries. Authors in [8] and [2] were among the first to identify the importance of such instability mechanisms in setting the BJT.

Using a theoretical model in [9] it is affirmed that the BJT can be represented by the Kutateladze number given that this dimensionless group includes the basic forces that determines that transition, namely gas inertial forces, bubble buoyancy forces, and tension forces. These authors postulate that the BJT takes place when the upward acceleration of the liquid is null at the top of the liquid 
level. For vertical tubes in [10] it is reported that the BJT occurs for $\mathrm{Ku}=3.1$. The critical gas velocity between the bubbling regime and the jetting regime is correlated in [11] with the liquid phase Weber number and the gas phase Reynolds number based on the gas velocity at the nozzle. In accordance to [2] the critical injection velocity for jet instability depends on surface tension, tuyere diameter, and the gas-to-liquid density ratio, which can be summarized by the Weber number.

In [12] is studied the BJT phenomenon for large nozzles submerged in water. It is reported that the transition velocity greatly decreases with the increase of nozzle diameter for nozzle diameter less than $0.01 \mathrm{~m}$. However, for larger nozzle diameters the effect of nozzle diameter on the transition velocity is insignificant. The effects of the surface roughness of the orifice and the orifice angle on the BJT in a bubble column are experimentally considered in [13] over a wide range of nozzle gas velocities. In accordance to these authors the transition velocity at an orifice plate with an orifice angle of $0-\pi / 2$ increases with increasing orifice angle, whereas the regime-transition velocity at an orifice plate with an orifice angle of $\pi / 2-\pi$ decreases with increasing orifice angle. Besides, the transition velocity is increased as the orifice surface roughness is increased.

In [14] the problem of absolute instability is mathematically analyzed in order to explain the BJT phenomenon. When the gas flow rate is increased the bubbles in the plume coalesce and a gas jet is formed. However in the subsonic region $(\mathrm{M}<1)$ absolute instability was found and therefore the formed jet always breaks up into bubbles. The gas jet does not disintegrate until it reaches some distance from the nozzle, where the jet breaks up into a column of rising bubbles. Given that no absolute instability was found in the supersonic region the gas jet remains stable. In [15] nitrogen gas was injected into a mercury bath through an orifice located at the bottom of a transparent vessel. The orifice diameter and the gas-flow rates were varied and the gas system was observed using a high speed film camera. The BJT takes place in a transitional gas-flow range. Jetting is initiated at a critical gas-flow rate for each orifice diameter. The authors report that the value of the critical gas-flow velocity is a little bit larger than but very close to the nominal sonic velocity $(M=1)$ irrespectively of the orifice diameter. In [16], the jetting behavior of nitrogen jets injected into water bath is studied. The gas jet behavior was directly observed by means of a high speed cine-camera. It is reported that BJT begins to occur when the gas flow velocity at the exit of an orifice exceeds the sonic velocity, i.e. the BJT nitrogen gas jets injected into water takes place in the sonic region. In accordance to [17], the BJT takes place only in the sonic region and occurs more easily with increasing the ratio of gas to liquid densities.

An experimental identification of regimes of bubbling and jetting at the orifices of distillation plates was carried out in [18] using visual and high speed photography. Six distinct regimes (perfect bubbling, deformed bubbling, imperfect bubbling, steady jet, unstable jet, pulsating jet) were identified. Each regime is determined by the liquid depth and the air velocity through the hole. The BJT 
in a nitrogen-water system was studied experimentally in [19]. The gas-liquid system was considered a complex dynamics system and the generated time series were analyzed using mathematical chaos theory. The transition regime showed an intermittent character and the BJT was indicated by a sudden drop of the Kolmogorov entropy.

An interesting experimental work on submerged air jets was carried out by [1]. Air jets were injected through nozzles at the bottom of a stagnant liquid pool. Several velocities, nozzle diameters and liquids were employed in the experiments. The jet formation velocity and jet lengths at different liquids and with different nozzles were measured by video recording and image processing. Two distinct regime transitions, bubbling to jetting and jetting to bubble plume were observed by the authors. In accordance to them the transition velocity is increased as the nozzle diameter is decreased. Besides, jet length is a linear function of the jet velocity at subsonic injection velocities and the formation of the jets is adversely affected by large liquid viscosity.

In this work, the bubbling to jetting transition during the bottom injection of argon in molten steel contained in a cylindrical vessel at subsonic velocities is numerically simulated by means of Computational Fluid Dynamics (CFD). 2D isothermal transient computer simulations were carried out. The injection velocity, the height of molten steel, the diameter of the injection nozzle, and the viscosity of molten steel were varied in order to observe the bubbling to jetting transition. From the CFD phase distribution results the height of the formed jet is estimated. For the argon-molten steel system the injection velocity at which the bubbling to jetting transition occurs in the subsonic regime is determined. Besides, a second transition from jetting to bubbling due to the jet instability at subsonic velocities is studied.

\section{Methodology}

The Computational Fluid Dynamics (CFD) technique [20] is employed in order to study the Bubbling to Jetting Transition (BJT). Argon is injected into molten steel through a nozzle located at the bottom of a cylindrical vessel at subsonic velocities. The process is considered isothermal. The equations of continuity and momentum [21], the K- $\varepsilon$ model for turbulence [22] and the Volume of Fluid model for multiphase flow [23] are employed in the CFD numerical simulations. The diameter and height of the vessel are $2 \mathrm{~m}$ and $3 \mathrm{~m}$, respectively. Meshing of the geometrical model yielded 13,149 trilateral cells.

The effect of the molten steel height, the subsonic injection velocity, the nozzle diameter, and the molten steel viscosity on the jet height and the BJT is numerically analyzed. Five subsonic injection velocities $\left(\mathrm{v}_{\mathrm{i}}\right)$ are considered: 5, 25, 50,100 and $150 \mathrm{~m} / \mathrm{s}$. Table 1 shows the corresponding Mach numbers assuming a value of $343.2 \mathrm{~m} / \mathrm{s}$ for the speed of sound. Three values of the metal height $\left(\mathrm{H}_{\mathrm{m}}\right)$ are considered: $1.5,2$ and $2.5 \mathrm{~m}$. Three values of the nozzle diameters $\left(\mathrm{d}_{\mathrm{n}}\right)$ are as follows: $0.001,0.005$ and $0.01 \mathrm{~m}$. Finally, three values of the molten steel 
Table 1. Mach number corresponding to the considered injection velocities.

\begin{tabular}{cc}
\hline Injection velocity, $\mathrm{m} / \mathrm{s}$ & Mach number $(\mathrm{M})$ \\
\hline 5 & 0.0146 \\
25 & 0.0728 \\
50 & 0.1457 \\
100 & 0.2914 \\
150 & 0.4371 \\
\hline
\end{tabular}

viscosity $\left(\mu_{\mathrm{m}}\right)$ are assumed: $0.0067,0.1$ and $1 \mathrm{~kg} /(\mathrm{m} \cdot \mathrm{s})$. The values of the physical properties of argon and molten steel are shown in Table 2.

\section{Results and Discussion}

Figure 1 shows the phase distributions for four values of the injection velocities. The flow regimes are clearly shown. Bubbling regime is observed in Figure 1(a) corresponding to an injection velocity of $5 \mathrm{~m} / \mathrm{s}$, whereas for 50,100 and $100 \mathrm{~m} / \mathrm{s}$ two regimes (jetting and jetting to bubbling) are appreciated in Figures 1(b)-(d), respectively. BJT occurs for an injection velocity less than $25 \mathrm{~m} / \mathrm{s}$. The jetting regime will remain until a certain value of the vertical coordinate which is named here as "jet height", $H_{j}$. At subsonic velocities $(M<1)$ the jetting regime is unstable [14] and for $\mathrm{y}>\mathrm{H}_{\mathrm{j}}$ the continuous jet is transformed into a bubble stream, as is observed in Figure 1. Jet heights were determined from the phase distributions and are depicted in Figure 2 as function of the injection velocity assuming that $\mathrm{H}_{\mathrm{m}}=2 \mathrm{~m}, \mathrm{~d}_{\mathrm{n}}=0.001 \mathrm{~m}$ and $\mu_{\mathrm{m}}=0.0067 \mathrm{~kg} /(\mathrm{m} \cdot \mathrm{s})$. In the jetting regime $\left(\mathrm{v}_{\mathrm{i}} \geq\right.$ $25 \mathrm{~m} / \mathrm{s}$ ) the dependence of the jet height on the injection velocity is almost linear, in accordance with the experimental results of [1]. Argon volume fraction in the jets as function of the injection velocity along the horizontal coordinate is shown in Figure 3 for $\mathrm{y}=0.25 \mathrm{~m}$ and $\mathrm{H}_{\mathrm{m}}=2 \mathrm{~m}, \mathrm{~d}_{\mathrm{n}}=0.001 \mathrm{~m}$ and $\mu_{\mathrm{m}}=0.0067$ $\mathrm{kg} /(\mathrm{m} \cdot \mathrm{s})$. Figure 3 shows that the argon volume fraction exhibits a Gaussian distribution inside the jets as reported experimentally in [24] and numerically in [25] [26]. Besides, in Figure 3 it is observed that the volume fraction and the width of the jets are increased as the injection velocity is increased.

Due to gravity molten metal in the vessel exerts a metallostatic force in all direction of the liquid which depends on the metal height and the molten metal density [27]. This force acts in opposition to the vertical inertial forces of the gas injected at the bottom of the vessel. As the height of the molten metal in the vessel in increased the metallostatic force will be greater, and as consequence the height of the jet will be smaller. This is corroborated in Figure 4 using an injection velocity of $50 \mathrm{~m} / \mathrm{s}, \mathrm{d}_{\mathrm{n}}=0.001 \mathrm{~m}$ and $\mu_{\mathrm{m}}=0.0067 \mathrm{~kg} /(\mathrm{m} \cdot \mathrm{s})$. Quantitative results are depicted in Figure 5.

The effect of the nozzle diameter on the phase distribution, the jet height and the jetting to bubbling transition is observed in Figures 6(a)-(c) for nozzle diameters of $0.001,0.005$ and $0.1 \mathrm{~m}$ considering an injection velocity of $25 \mathrm{~m} / \mathrm{s}, \mathrm{H}_{\mathrm{m}}$ $=2 \mathrm{~m}$ and $\mu_{\mathrm{m}}=0.0067 \mathrm{~kg} /(\mathrm{m} \cdot \mathrm{s})$. Turbulence of the molten metal is notoriously 


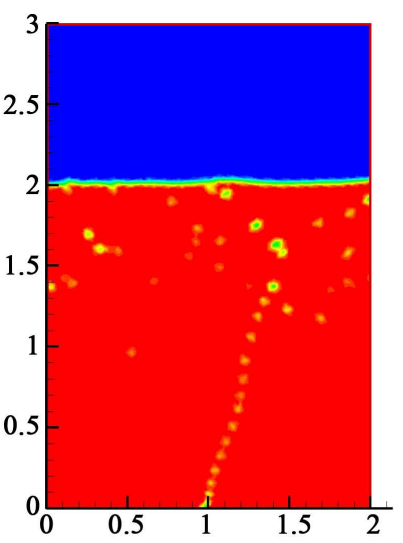

(a)

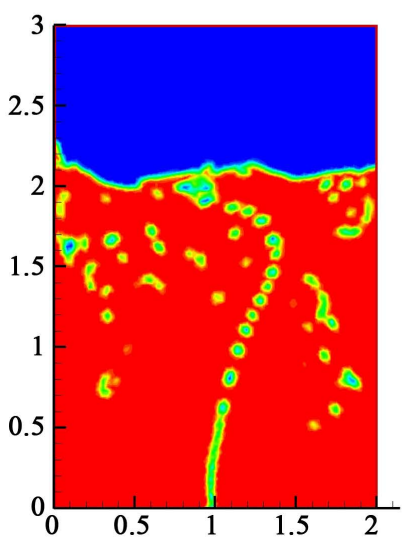

(c)

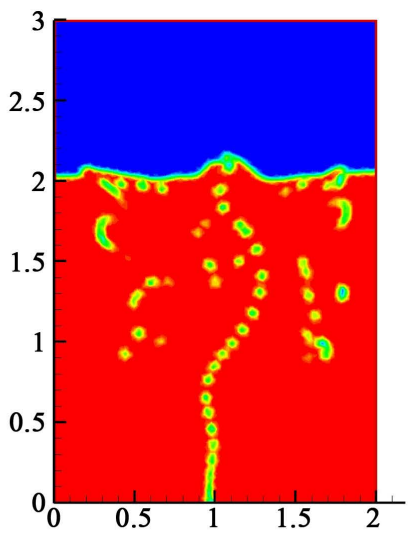

(b)

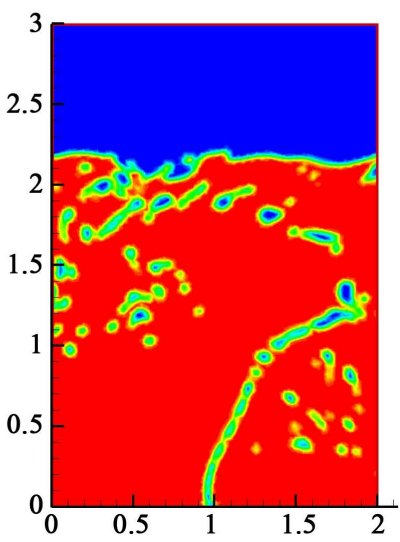

(d)

Figure 1. Phase distributions for different injection velocities. Argon is the blue phase, molten steel is the red phase. (a) $5 \mathrm{~m} / \mathrm{s}$; (b) $25 \mathrm{~m} / \mathrm{s}$; (c) $50 \mathrm{~m} / \mathrm{s}$; (d) $100 \mathrm{~m} / \mathrm{s}$.

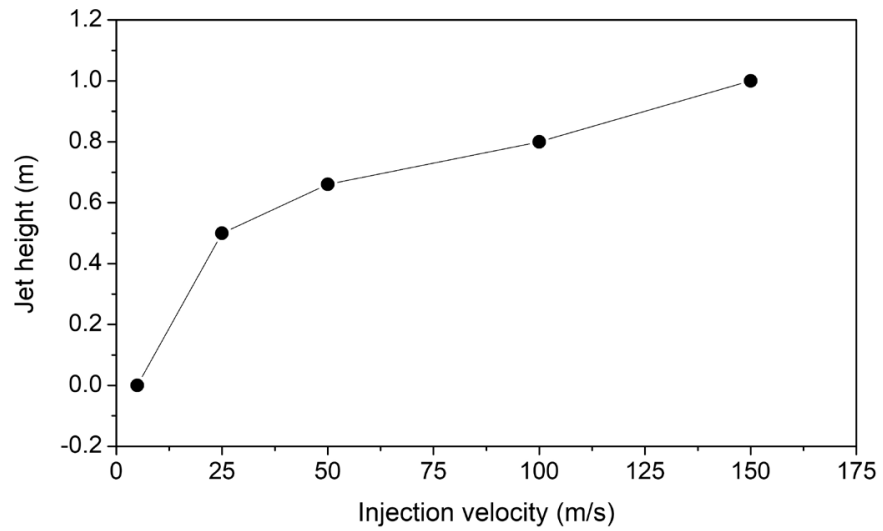

Figure 2. Jet height as function of the injection velocity.

Table 2. Physical properties of the involved phases.

\begin{tabular}{ccc}
\hline Property & Molten steel & Argon \\
\hline Density, $\mathrm{kg} / \mathrm{m}^{3}$ & 7100 & 1.6228 \\
Viscosity, $\mathrm{kg} /(\mathrm{m} \cdot \mathrm{s})$ & $0.0067,0.1,1$ & $2.125 \times 10^{-5}$ \\
Surface tension, $\mathrm{N} / \mathrm{m}$ & 1.69 & - \\
\hline
\end{tabular}




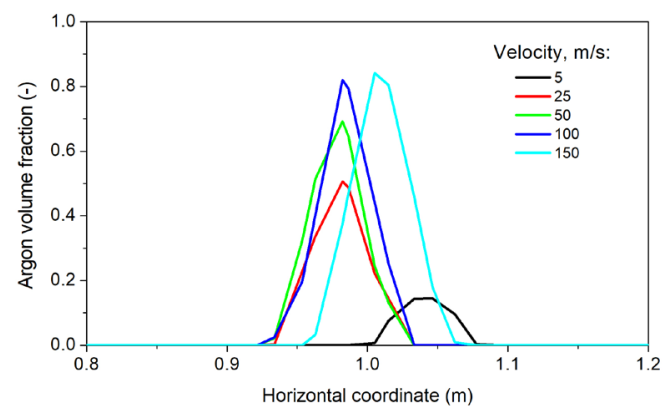

Figure 3. Argon volume fraction in the jets as function of the injection velocity.

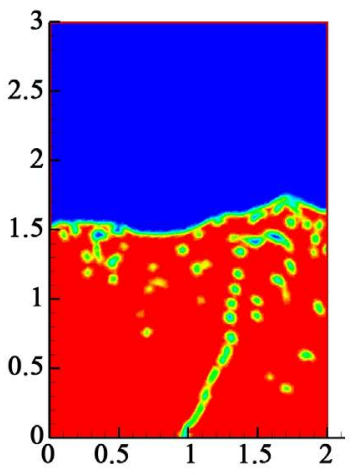

(a)

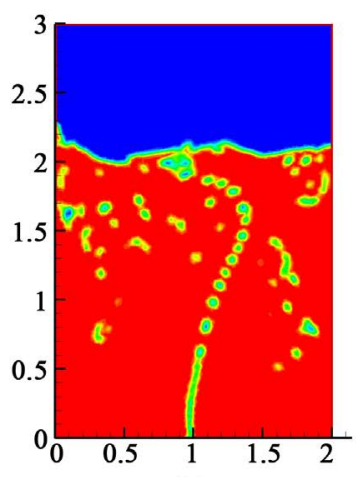

(b)

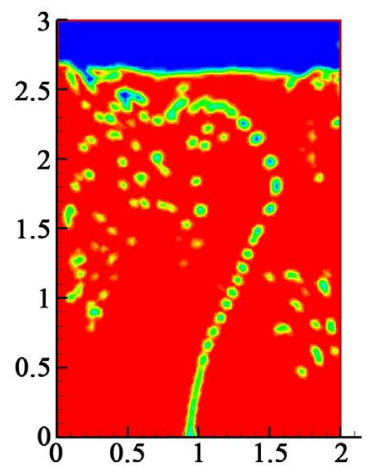

(c)

Figure 4. Phase distributions for different values of the molten steel height. Argon is the blue phase, molten steel is the red phase. (a) $\mathrm{H}_{\mathrm{m}}=1.5 \mathrm{~m}$; (b) $\mathrm{H}_{\mathrm{m}}=2 \mathrm{~m}$; (c) $\mathrm{H}_{\mathrm{m}}=2.5 \mathrm{~m}$.

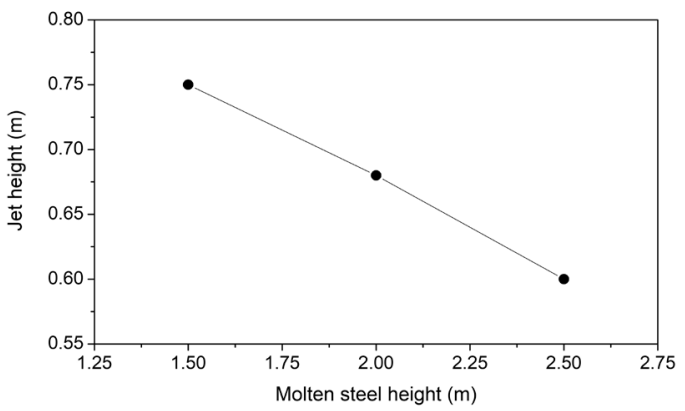

Figure 5. Jet height as function of the molten steel height.

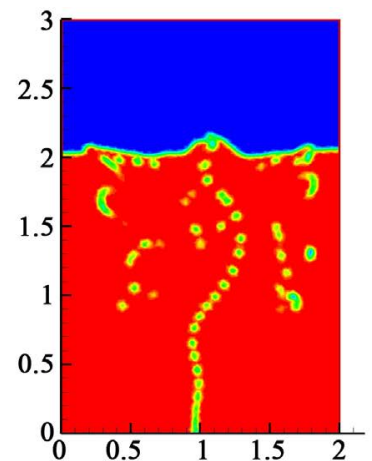

(a)

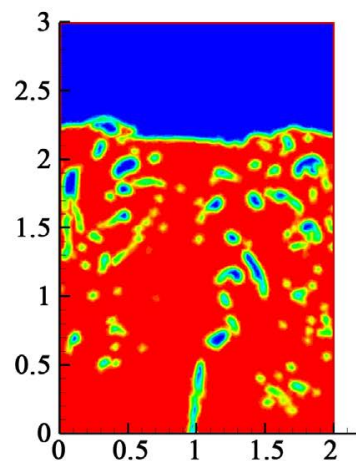

(b)

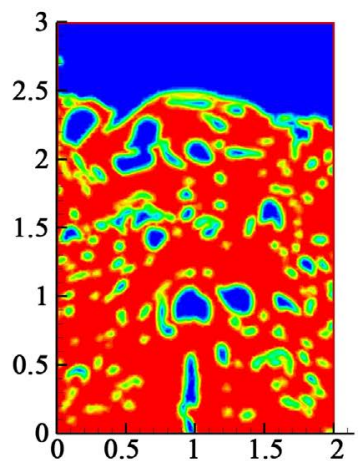

(c)

Figure 6. Phase distributions for several values of the nozzle diameter. Argon is the blue phase, molten steel is the red phase. (a) $d_{n}=0.001 \mathrm{~m}$; (b) $d_{n}=0.005 \mathrm{~m}$; (c) $d_{n}=0.01 \mathrm{~m}$. 
increased as the nozzle diameter is increased. In accordance to [28] [29] the bubble size is proportional to the nozzle diameter, and this effect is observed in Figure 6. Increasing the nozzle diameter maintaining constant the injection velocity, as is the case of Figure 6, is equivalent to an increase in the argon flow rate, as is shown in Table 3. This helps to explain the increase in the molten metal turbulence and the increase in bubble size [29]. At the end the jet height increases as the nozzle diameter is increased, as is summarized in Figure 7.

Viscous forces are in opposition to inertial forces during gas injection in liquids, and therefore liquid viscosity has a significant impact on the bubble size [30]. In accordance to [1] formation of gas jets are impeded in liquids with large viscosity. Therefore in liquids with extremely high viscosity the BJT may even disappear. CFD simulations were carried out in order to study the influence of the molten steel viscosity on jet height and BJT. Three values of viscosity, namely $0.0067,0.1$ and $1 \mathrm{~kg} /(\mathrm{m} \cdot \mathrm{s})$ were considered which cover the viscosity of molten steel in a wide range of temperatures [31] assuming an injection velocity of 25 $\mathrm{m} / \mathrm{s}$. Results are depicted in Figures 8(a)-(c). Observing this figure no significant effect of viscosity on jet height and flow pattern is appreciated for the values of viscosity considered.

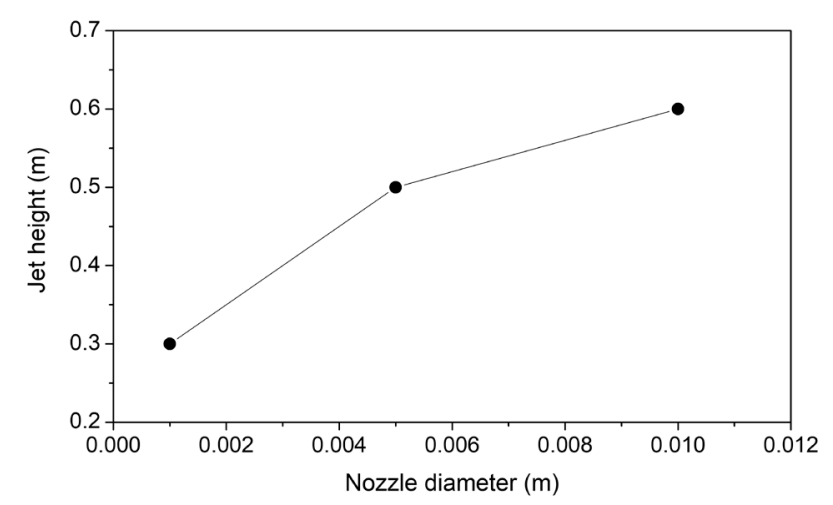

Figure 7. Jet length as function of the nozzle diameter for $v_{i}=25 \mathrm{~m} / \mathrm{s}$.

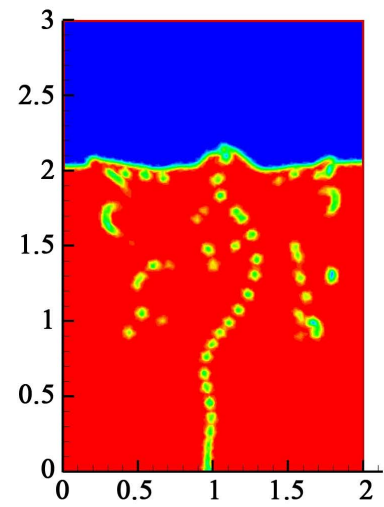

(a)

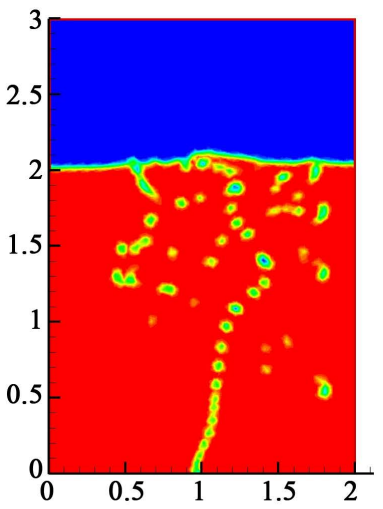

(b)

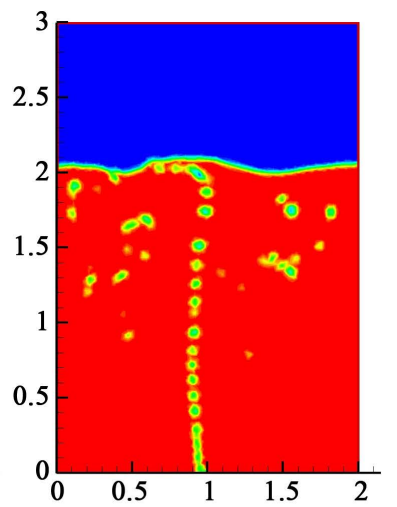

(c)

Figure 8. Phase distributions as function of the molten steel viscosity. Argon is the blue phase, molten steel is the red phase. (a) $\mu_{\mathrm{m}}=0.0067 \mathrm{~kg} /(\mathrm{m} \cdot \mathrm{s}) ;$ (b) $\mu_{\mathrm{m}}=0.1 \mathrm{~kg} /(\mathrm{m} \cdot \mathrm{s}) ;$ (c) $\mu_{\mathrm{m}}$ $=1 \mathrm{~kg} /(\mathrm{m} \cdot \mathrm{s})$. 
Table 3. Argon flow rates for the nozzle diameters considered.

\begin{tabular}{ccc}
\hline Nozzle diameter, $\mathrm{m}$ & Injection velocity, $\mathrm{m} / \mathrm{s}$ & Argon flow rate, $\mathrm{m}^{3} / \mathrm{s}$ \\
\hline 0.001 & 25 & $1.9635 \times 10^{-5}$ \\
0.005 & 25 & $4.9087 \times 10^{-4}$ \\
0.01 & 25 & $1.9635 \times 10^{-3}$ \\
\hline
\end{tabular}

\section{Conclusion}

The bubbling to jetting transition was studied using Computational Fluid Dynamics numerical simulations under subsonic injection velocities during the argon injection in molten steel. The effect of the injection velocity, the height of molten steel, the diameter of the injection nozzle, and the viscosity of molten steel on the jet height was analyzed. From the numerical results, the following conclusions can be drawn: for the argon-molten steel system, the bubbling to jetting transition occurs for an injection velocity less than $25 \mathrm{~m} / \mathrm{s}$. At subsonic velocities, the formed jet is unstable and it is transformed into a bubble plume. The argon volume fraction in the jet is proportional to the injection velocity and it follows a Gaussian distribution. The jet height is increased as the diameter of the injection nozzle is increased whenever the injection velocity is kept constant. For the range of viscosities considered, the molten steel viscosity has no significant influence on the jet height and the bubbling to jetting transition. Future research must be done on the bubbling to jetting transition under sonic and supersonic injection velocities.

\section{Conflicts of Interest}

The authors declare no conflicts of interest regarding the publication of this paper.

\section{References}

[1] Syeda, S.R. and Ansery, A.M. (2014) Formation and Development of Submerged Air Jets. Journal of Mechanical Engineering, 44, 137-141. https://doi.org/10.3329/jme.v44i2.21721

[2] Zhao, Y.F. and Irons, G.A. (1990) The Breakup of Bubbles into Jets during Submerged Gas Injection. Metallurgical Transactions B, 21, 997-1003. https://doi.org/10.1007/BF02670270

[3] Pistorius, P.C. (2014) Bubbles in Process Metallurgy. In: Seetharaman, S., Eds., Treatise on Process Metallurgy. Volume 2: Process Phenomena, Elsevier, Waltham, 142. https://doi.org/10.1016/B978-0-08-096984-8.00019-7

[4] Kapusta, J.P.T. (2018) Sonic Injection in Sulphide Bath Smelting: An Update. The Journal of the Southern African Institute of Mining and Metallurgy, 118, 1131-1139. https://doi.org/10.17159/2411-9717/2018/v118n11a2

[5] Schwarz, M.P. (1996) Simulation of Gas Injection into Liquid Melts. Applied Mathematical Modelling, 20, 41-51. https://doi.org/10.1016/0307-904X(95)00109-W

[6] Weiland, C. and Vlachos, P.V. (2013) Round Gas Jets Submerged in Water. Inter- 
national Journal of Multiphase Flow, 48, 46-57. https://doi.org/10.1016/j.ijmultiphaseflow.2012.08.002

[7] Hoefele, E.O. and Brimacombe, J.K. (1979) Flow Regimes in Submerged Gas Injection. Metallurgical Transactions B, 10, 631-648. https://doi.org/10.1007/BF02662566

[8] Kitscha, J., Kocamustafaogullari, G. (1989) Breakup Criteria for Fluid Particles. International Journal of Multiphase Flow, 15, 573-588. https://doi.org/10.1016/0301-9322(89)90054-2

[9] Sundar, R. and Tan, R.B.H. (1999) A Model for Bubble-to-Jet Transition at a Submerged Orifice. Chemical Engineering Science, 54, 4053-4060. https://doi.org/10.1016/S0009-2509(99)00152-9

[10] Taitel, Y., Bornea, D. and Dukler, A.E. (1980) Modelling Flow Pattern Transitions for Steady Upward Gas-Liquid Flow in Vertical Tubes. AIChE Journal, 26, 345-354. https://doi.org/10.1002/aic.690260304

[11] Idogawa, K., Ikeda, K., Fukuda, T. and Morooka, S. (1987) Formation and Flow of Gas Bubbles in a Pressurized Bubble Column with a Single Orifice or Nozzle Gas Distributor. Chemical Engineering Communications, 59, 201-212. https://doi.org/10.1080/00986448708911995

[12] Cai, Q., Shen, X., Shen, C. and Dai. G. (2010) Large Submerged Orifices Using Electrical Capacitance Tomography (ECT). The Canadian Journal of Chemical Engineering, 88, 340-349.

[13] Irrgang, C., Hinrichsen, O. and Lau, R. (2012) Effects of Orifice Angle and Surface Roughness on the Bubbling-to-Jetting Regime Transition in a Bubble Column. Industrial \& Engineering Chemistry Research, 51, 4445-4451. https://doi.org/10.1021/ie202890u

[14] Chen, K. and Richter, H.J. (1997) Instability Analysis of the Transition from Bubbling to Jetting in a Gas Injected into a Liquid. International Journal of Multiphase Flow, 23, 699-712. https://doi.org/10.1016/S0301-9322(97)00003-7

[15] Mori, K., Ozawa, Y. and Sano, M. (1982) Characterization of Jet Behavior at a Submerged Orifice in Liquid Metal. Transactions ISIJ, 22, 377-384.

[16] Ozawa, Y. and Mori, K. (1983) Characteristics of Jetting Observed in Gas Injection into Liquid. Transactions ISIJ, 23, 764-768.

[17] Ozawa, Y. and Mori, K. (1986) Effect of Physical Properties of Gas and Liquid on Bubbling-Jetting Phenomena in Gas Injection into Liquid. Transactions ISIJ, 26, 291-297.

[18] Muller, R.L. and Prince, R.G.H. (1972) Regimes of Bubbling and Jetting from Submerged Orifices. Chemical Engineering Science, 27, 1583-1592. https://doi.org/10.1016/0009-2509(72)80051-4

[19] Ruzicka, M.C., Drahos, J., Zahradnik, J.D. and Thomas, N.H. (1997) Intermitent Transition from Bubbling to Jetting Regime in Gas-Liquid Two Phase Flows. International Journal of Multiphase Flow, 23, 671-682. https://doi.org/10.1016/S0301-9322(97)00009-8

[20] Ferziger, J.H. and Peric, M. (1999) Computational Methods for Fluid Dynamics. Springer, Berlin. https://doi.org/10.1007/978-3-642-98037-4

[21] Bird, R.B., Stewart, W.E. and Lightfoot, E.N. (2002) Transport Phenomena. Wiley, New York, N.Y.

[22] Launder, B.E. and Spalding, D.B. (1972) Mathematical Models of Turbulence. Academic Press, London.

[23] Hirt, C.W. and Nichols, B.D. (1981) Volume of Fluid (VOF) Method for the Dy- 
namics of Free Boundaries. Journal of Computational Physics, 39, 201-225.

https://doi.org/10.1016/0021-9991(81)90145-5

[24] Tacke, K.H., Schubert, H.G., Weber, D.J. and Schwerdtfeger, K. (1985) Characteristics of Round Vertical Gas Bubble Jets. Metallurgical Transactions B, 16B, 261-275. https://doi.org/10.1007/BF02679717

[25] Lima Neto, I.E. (2015) Self-Similarity of Vertical Bubbly Jets. Brazilian Journal of Chemical Engineering, 32, 475-487.

[26] Yin, Z.G., Jia, Q.Q., Li, Y., Wang, Y.X. and Yang, D.J. (2018) Computational Study of a Vertical Plunging Jet into Still Water. Water, 10, 1-20.

[27] Cengel, Y.A. and Cimbala, J.M. (2014) Fluid Mechanics. Fundamentals and Applications. 3rd Edition. McGraw-Hill, New York.

[28] Ghosh, A. (2001) Secondary Steelmaking. CRC Press, Boca Raton, FL.

[29] Thomas, B., Dennisov, A. and Bai, H. (1997) Behavior of Argon Bubbles during Continuous Casting of Steel. ISS 80th Steelmaking Conference, Chicago, 13-16 April 1997, 375-384.

[30] Zhang, W. (2014) Evaluation of Effect of Viscosity Changes on Bubble Size in a Mechanical Flotation Cell. Transactions of Nonferrous Metals Society of China, 24, 2964-2968. https://doi.org/10.1016/S1003-6326(14)63432-4

[31] Rywotycki, M., Malinowski, Z., Giełzecki, J. and Gołdasz, A. (2014) Modelling Liquid Steel Motion caused by Electromagnetic Stirring in Continuous Casting Steel Process. Archives of Metallurgy and Materials, 59, 485-492.

https://doi.org/10.2478/amm-2014-0080 